Article

\title{
Segmentation of Nature-Based Tourists in a Rural Area (2008-2009): A Single-Item Approach
}

\author{
Jinyang Deng ${ }^{1,2}$ and Jian $\mathrm{Li}^{1, *}$ \\ 1 School of Landscape Architecture, School of Tourism \& Health, Zhejiang Agriculture and Forestry \\ University, Hangzhou 311300, Zhejiang, China; jinyang.deng@mail.wvu.edu \\ 2 Recreation, Parks, \& Tourism Resources Program, School of Natural Resources, West Virginia University, \\ Morgantown, WV 26506, USA \\ * Correspondence: lijian@zafu.edu.cn
}

Received: 11 February 2019; Accepted: 2 April 2019; Published: 6 April 2019

check for updates

\begin{abstract}
Although much research on nature-based tourism (NBT) has been conducted in natural areas, such as national parks and other protected areas, studies on NBT in rural areas have been limited. Moreover, few NBT studies, if any, have examined the impact of seasons and/or locations on visitors' perceptions of NBT. This comes as little surprise, given that naturalness, the fundamental core of NBT, is likely to vary with seasons and locations. To this end, this study examines NBT in a rural area in the Appalachian Region, USA, with a focus on market segmentation, based on data collected from a four-season on-site survey of 2692 visitors. Different from many other tourism market studies where multiple-item measures are used, this study uses a single-item measure on natural observation/study to identify NBT segments. Analysis of variance, Chi-square analysis, and discriminant analysis are used to confirm NBT segments and determine the effectiveness of the use of the single-item approach for segmentation. The results show that the single-item approach is effective to differentiate visitors by their socio-demographics and trip characteristics, with findings being consistent with NBT studies in natural areas. It is worth noting that people's responses to questions on natural observation/study vary with seasons and locations, suggesting that different perceptions of natural affinity may arise from the differences in seasons and locations with different levels of natural elements. Theoretical, methodological, and managerial implications are discussed.
\end{abstract}

Keywords: nature-based tourism; rural areas; single-item measure; natural observation

\section{Introduction}

Nature-based tourism (NBT) can be simply defined as all forms of tourism that take place in natural areas [1,2]. Although NBT is usually perceived to involve tourism activities in relatively uncontaminated areas, such as national parks, wilderness areas, and other protected areas that are geographically remote with high levels of biodiversity concentration [3,4], it can also be carried out in rural or even urban areas [5] that involve varying degrees of naturalness, ranging from developed landscape with lower naturalness and more human modification (e.g., urban parks) to natural areas with higher naturalness and less human modification (e.g., state parks, state forests, and national forests). Recent research shows that visitors tend to demand more services and facilities even in a natural environment [6]. Line and Costen [7] also consider NBT destinations to include a place such as a city-park dyad that is "comprised of a protected, undeveloped natural area, and a relatively more developed, geographically proximal gateway city" (p. 2).

While NBT has been widely examined in natural areas, such as national parks and other protected areas, it has been under-researched (particularly in terms of market segmentation) in rural areas. Moreover, few studies, if any, have examined visitors' perceptions of a NBT destination from season to 
season and/or from location to location. The same natural area may be perceived differently between winter and summer or between spring and fall. Similarly, visitors' perceptions may also vary with locations that feature different levels of perceived naturalness. Thus, the identification of who are nature-based tourists (NBTs) may largely depend on the circumstances involved. To this end, this study attempts to accomplish the following: (1) identify who are NBTs in a rural area using a single-item approach; (2) test the effectiveness of the single-item approach for segmentation; (3) examine the extent to which season and location may affect perceptions of NBTs; and (4) compare the segmentation effectiveness between a single-item approach and a multi-item approach.

Garrett County, Maryland, a rural area in the Appalachian Region of the United States, was chosen as the study area for three reasons. First, the county is a four-season destination that allows for a seasonal comparison of NBT perceptions. Second, it is one of the most rural areas in the state of Maryland with $83.9 \%$ of its population living in rural areas. Third, the county provides numerous recreational opportunities with different levels of naturalness as will be described in the latter part of this paper (see Section 3). Thus, the county is an ideal destination to examine visitors' perceptions of rural NBT by seasons and locations as well.

Garrett County, as one of the most important NBT destinations in the Appalachian region, has many natural and cultural assets that attract millions of domestic and international tourists each year. As with many other counties across the Appalachian region, tourism has been playing an increasingly important role in promoting and revitalizing the county's economy. In order to remain competitive in the tourism market, it is necessary to identify the tourism demand and to see if it matches with the tourism supply in the area. This requires that a comprehensive and systematic survey be conducted for the county. To this end, the Recreation, Parks, and Tourism Resources Program of West Virginia University was contracted by the Garrett County Chamber of Commerce to conduct a four-season survey at varying locations within the county.

The data were collected during the period of 2008-2009, which may seem to be a little old. There are two reasons for the late publication of the data. First, as a contracted project, we do not own the data, and thus, we could not use the whole data immediately after the completion of the data collection. Second, we were expecting a second-round replica survey to be conducted so that we would be able to reference a comparative study that uses data from both rounds of the survey. With this expectation/hope in mind, we held the data for several years and did not start writing this paper until two years ago, when we felt there was no longer any such hope of conducting a replica survey. It is when we finished this paper, however, that the chance to conduct a second-round survey finally came in 2019. However, as with the first-round survey, we do not own the data, which will inevitably delay the use of the second-round data for academic publication. Therefore, we thought it wise to publish this paper based solely on the first-round data. Although the data are a little old, it should not be a big issue, given that the nature of this study is not time sensitive. Arguably, people's attitudes/motivations may be similar or relatively unchanged over a short time period, and thus, the use of attitudinal/motivational data in this study may still be appropriate for market segmentation.

The following sections of this paper are organized as follows. We begin with a review of the literature on the conceptual aspects of NBT and ecotourism, as well as methods used to segment NBT, followed by a description of the methods used in this paper. We then present results, along with a discussion of findings and theoretical, methodological, and managerial implications. In addition, research limitations and future research needs are also presented.

\section{Literature Review}

\subsection{Nature-Based Tourism and Ecotourism}

While a detailed review of the concepts and definitions related to NBT and ecotourism is beyond the scope of this paper, a brief discussion of the two concepts is still necessary to provide a contextual link to what this study aims to accomplish. As mentioned above, NBT can be broadly defined as any 
forms of tourism that occur in a natural environment. This definition of NBT centers on the tourism setting being natural. Because of its descriptive nature, there is not much debate among researchers on how NBT should be defined. In contrast, ecotourism has been defined differently by different people. Although ecotourism, by default, is a form of NBT, researchers tend to take the natural component for granted while turning attention to its normative aspects, such as environmental education/learning, sustainability (ecological/environmental, socio-cultural, or economic), conservation, responsibility, community involvement, local wellbeing, and ethics, among others. This value-laden nature of ecotourism makes it difficult to achieve a universal consensus among researchers. That said, it is generally accepted that ecotourism should involve three key components: nature-based activities or location, environmental education/learning, and sustainability, albeit opinions are still divergent as to which aspect of sustainability—ecological/environmental, socio-cultural, or economic—should be used to define ecotourism.

While recognizing that NBT and ecotourism are conceptually different, they are both inherently "natural resource dependent' [8] (p. 639). Hall [9] argues that "nature-based tourism is ultimately based upon the factors that allow an area to display the characteristics of perceived and actual naturalness" (p. 106). Thus, naturalness, as the fundamental core of both NBT and ecotourism, may explain why the two terms have been interchangeably used in the literature. This is particularly the case when it is hard to distinguish a NBT from an ecotourist if they are both pursuing the same tourism activity at the same time and at the same natural setting. Following this line of reasoning, NBT and ecotourism are also interchangeably used in this paper.

\subsection{Segmentation of Nature-Based Tourists/Ecotourists}

Two general types of methods, data driven segmentation and a priori segmentation, have been used in the literature to segment tourism markets [10-12]. Data-driven segmentation typically uses multivariate analysis, such as cluster analysis, to classify respondents into groups with similar characteristics based on a set of selected variables, while the priori segmentation approach uses prior knowledge or predetermined criteria to divide respondents into subpopulations. Variables used in the data-driven approach usually involve psychographic measures (i.e., personality traits, perceptions, attitudes, motivations, benefits, and social or environmental values), while tourists' socio-demographics (e.g., age, gender, education, and income) and trip characteristics (i.e., travel purpose, past experience, group size, activities, and spending) are typically used in the priori segmentation, although psychographic variables have also been used in some studies [13,14].

A recent trend shows that researchers are becoming increasingly interested in identifying and segmenting ecotourists or NBTs by their psychographic characteristics, such as NBT motivation or interests [15] or social or environmental attitudes/values [16-18]. For example, one study [19] identified four types of NBTs (i.e., casual, mainstream, dedicated, and hard-core) based on tourists' interests in nature. In another study [20], visitors who were primarily motivated to learn about nature and to commit at least one-third of the trip to nature travel were identified as ecotourists. In terms of classifying ecotourists based on their environmental attitudes, four types of ecotourists were classified in a study [18] based on their responses with respect to the New Ecological Paradigm (NEP) scale [21]: "concerners" (10.5\%), "approvers" (11.5\%), "disapprovers" (44.6\%), and "scepticals" (33.4\%).

Arguably, the psychographic approach of market segmentation has its foundation on the means-end chain theory, which describes a hierarchical linkage among product attributes (the means), functional consequence (tangible benefits), psychological consequence (emotional benefits), and personal values (the end) [22]. The means-end chain theory has been widely used in marketing research to determine values-based motivations towards consumption. However, only a few studies have applied this theory to the context of tourism. López-Mosquera and Sánchez [23] applied the theory to examine green space users' personal values through their perceived benefits of urban green attributes. Jiang et al. [24] used the theory to identify travel motivations of Chinese outbound tourists and to understand why these motivations are important to them. More recently, Kim et al. [25] 
also used the theory to understand individuals' perceived importance of pilgrimage attributes and identified a pilgrim value system. These studies indicate that attribute importance of a product/service plays an essential role in the formation of a hierarchical value system.

While most studies have used multiple-item scales to identify ecotourists (e.g., classification of geotravelers based on their overall scores on the Geotraveler Tendency Scale [11]; classification of ecotourists using such variables as age, traveling, organization of the event, budget, and type of tourism [26]; the hard-soft continuum of ecotourists based on their environmental commitment, trip characteristics, and services required [27]), a single-item scale has also been used in several studies [16,28-31]. For example, one study [30] identified NBTs by asking respondents to indicate their interest in natural places using a five-point Likert scale $(1=$ strongly agree, $5=$ strongly disagree). A second study [28] divided travelers based upon their responses to a single question "On holiday the efforts to maintain unspoiled surroundings play a major role for me." A third study [32] classified environmentally responsible tourists based on their willingness to pay a premium price for environmentally responsible tour operators. Finally, a fourth study [31] used a self-identification approach to identify ecotourists by asking one question on how much respondents considered themselves to be ecotourists. A similar approach was also used to classify the West Virginia tourism market into three segments: non-ecotourists, ecotourists-medium, and ecotourists-high [16].

Following the above review, this study applies the priori segmentation approach wherein visitors are divided into subgroups based on a single trip characteristic: motivation to observe and learn about nature. The NBT segments are then compared and confirmed based on their perceived attribute importance of attractions and local products.

\section{Methods}

\subsection{Study Area}

The study area is Garrett County, Maryland, USA. The county is located in the northwestern edge of the state with a population of 30,097 [33] — the third least populous county in the state. Garrett County is an all-year-round tourism destination with over 76,000 acres $\left(310 \mathrm{~km}^{2}\right)$ of lakes, state parks, and publicly accessible forestland and 20 National Register of Historic Places. Popular activities include camping, hiking, rock climbing, skiing, hunting, rafting, and horseback riding, among others. Tourism accounts for about $10 \%$ of the county's total employment and is the third largest employer, following educational and health services (19\%) and construction (13\%) [33]. Surveys were conducted at 21 different locations (Figure 1) determined by the Garrett County Chamber of Commerce as the most representative of the county's tourism attractions. These 21 locations included state parks, festivals/events, restaurants, shopping centers, antique stores, farm markets, and skiing and man-made whitewater rafting resorts. 


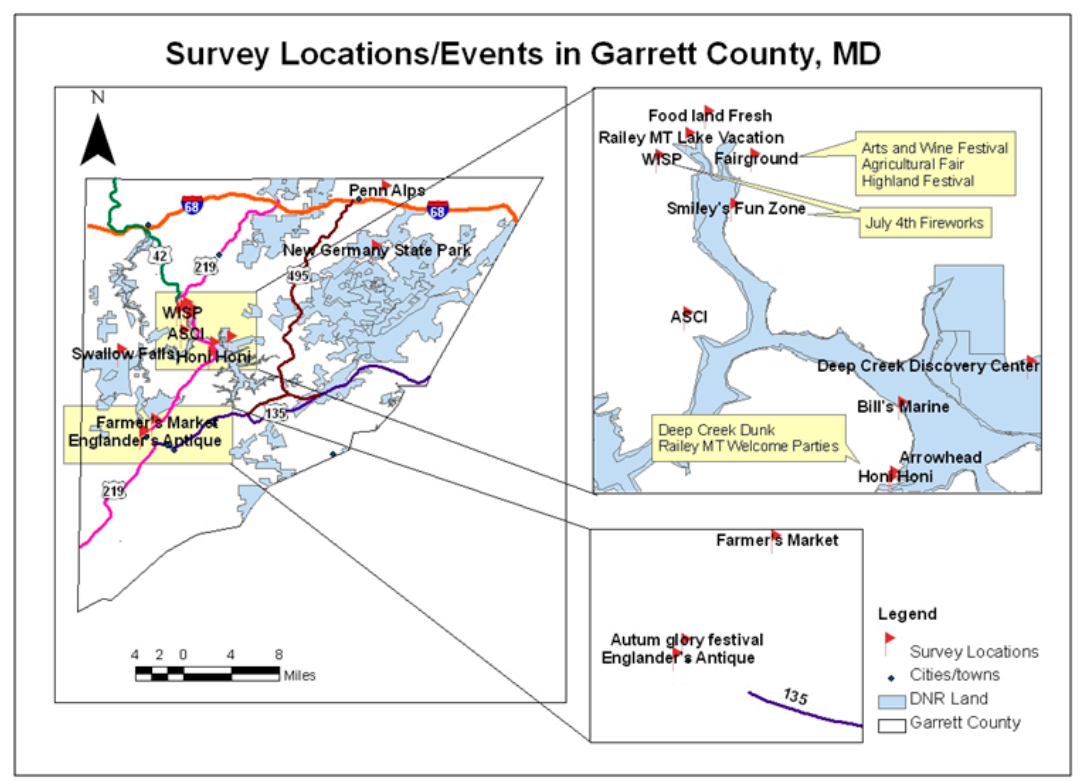

Figure 1. Survey locations in Garrett County, Maryland (ASCI: Adventure Sports Center International; WISP: Winter Sports).

\subsection{Sample}

This is a four-season, face-to-face, on-site, self-administered survey that started in August 2008 and ended in July 2009. A total of 2400 visitors were proposed to be surveyed with 600 visitors for each season to achieve a sampling error of $3 \%$.

A questionnaire was developed by drawing upon findings from tourism literature [34-36] and with inputs from the Garrett County Chamber of Commerce. This questionnaire is composed of six sections: visitors' trip characteristics; tourism activities and shopping behavior, visitors' perceptions of Garrett County as a tourism destination; visitors' wants and needs for commercial attractions; visitors' spending in Garrett County; and background information. Before the actual survey was started in August 2008, the questionnaire was pre-tested at two locations (i.e., McHenry Visitor Center and the Oakland Station and Visitor Center) in the county.

Visitors were approached at 21 locations by a survey team made up of graduate and undergraduate students majoring in recreation, parks, and tourism resources. Discount coupons were used as an incentive to encourage participation. Surveys were mostly conducted on Fridays, Saturdays, and Sundays from 9:00 to 17:00. The three-day survey period has also been used by other researchers [7].

The convenience sampling method was used to target respondents [37]. Specifically, survey administrators first introduced themselves and the purpose of the study before asking visitors whether they were willing to participate or not. If a visitor was unwilling to participate, another individual was then approached. If a visitor was willing, the questionnaire was presented to him/her for on-site completion.

\subsection{Measurement}

Perceived importance of attractions was measured by 14 items and perceived importance of products were measured by 12 items using a 5-point Likert scale $(1=$ not important at all, 3 = moderately important, 5 = extremely important). The 14 items measuring visitors' perceptions of the importance of attractions/resources include camping, farm tours/corn maze, historical sites, festivals/events, golf courses, trails, scenery (mountain, river), ski resort, artificial whitewater course, state parks/state forests, water sports, fall foliage, fishing, and real estate tour/search. The 12 items on perceived importance of products relate to local food products, books and music, collectibles/jewelry, 
art galleries, antiques, souvenirs, local-made products, glassware/pottery, Amish products, sporting goods, Sunday sales of alcohol, and dining out. In addition, visitors' motivations were measured using 10 items (i.e., opportunities for children, have a good time with family, rural life activities, local flavor experience, foul weather activities, opportunities to learn/to be edu-tained, adventure seeking, entertainment/theater, nature observation/study, and rest/relaxation) on a 5-point Likert scale ( $1=$ strongly disagree, $3=$ neutral, $5=$ strongly agree). Specifically, visitors were asked to indicate the extent to which each of these 10 items could meet their wants and needs during their trip in the county.

The single item "nature observation/study" from the motivation measurement was used to define NBTs. According to the literature [38], adventure tourism, wildlife tourism, ecotourism, and NBT are different types of tourism in natural areas, with NBT focusing on "the study and/or observation of the abiotic (nonliving) part of the environment, e.g., the rocks and landforms, as well as the biotic (living) component of it, e.g., fauna and flora"). Thus, it is appropriate to identify NBTs using the single item measuring nature observation/study.

\subsection{Data Analysis}

All data were analyzed using SPSS 24.0 with pairwise deletion. Data analyses consisted of five steps. First, the 14 items measuring perceived importance of attractions, 12 items measuring perceived importance of products, and 10 items measuring visitors' motivation to visit the destination were factor analyzed using principal component analysis (with varimax rotation and an eigenvalue of 1.00 or more for the identification of potential factors). The Kaiser-Meyer-Olkin (KMO) measure of sampling adequacy and Bartlett's test of sphericity were used to determine the appropriateness for factor analysis. A cut-off point of 0.45 (20\% overlapping variance) was used to determine items for a factor [39]. The reliability of a factor was estimated using Cronbach's alpha coefficients. Although the Cronbach's alpha value of 0.70 [40] has been commonly accepted as the cut-off point for indicating a scale's reliability, a lower value of 0.60 or even lower is also considered acceptable, especially in exploratory studies in social sciences and psychology [41,42].

Second, NBTs were classified into four types, casual, mainstream, dedicated, and hard-core, based on their responses to the single item measuring visitors' motivation for natural observation and study $(1=$ strongly disagree, $5=$ strongly agree). Specifically, those who responded negatively (strongly disagree or disagree) to the single motivation item were classified as casual. These visitors had a lower level of interests in nature, which is conceptually similar to the casual category defined in the literature [19]. In contrast, respondents on the remaining three categories, "neutral", "agree", and "strongly agree", were classified as mainstream, dedicated, and hard-core NBTs, respectively. These four types of NBTs were then reclassified into three levels: NBTs_Low, NBTs_Medium, and NBTs_High, following the methodology of two other studies [11,16], with the categories of casual and mainstream being combined as NBTs_Low, dedicated as NBTs_Medium, and hard-core as NBTs_High, based on ANOVA results. One study [43] classified geotravelers into three segments based on their overall scores on the Geotraveler Tendency Scale (i.e., scores lower than 4.5 as low/minimal geotravelers, scores from 4.5 to 5.5 as medium/moderate geotravelers, and scores higher than 5.5 as strong/strong geotravelers). Similarly, another study [16] classified self-identified ecotourists into three levels (i.e., non-ecotourists, ecotourists-medium, and ecotourists-high) based on participants' responses to the single question "To what extent do you consider yourself as an ecotourist?" ( 1 = strongly disagree, 5 = strongly agree).

Third, chi-square analyses were conducted to examine if the three levels of NBTs differ by socio-demographic variables, such as gender, age, education, and income, or by trip characteristics, such as past experience, season, location, and with/without kids. An adjusted residual greater than 1.96 or less than -1.96 ( \pm 2.0 is used by convention) was used to indicate if the number of cases in a cell is significantly larger or smaller than would be expected [44]. 
Fourth, NBTs were also classified into two groups based on the first factor scores (i.e., nature-based and learning) of the motivation measure, with scores less than 4 classified as the low level of NBTs and scores greater than 4 as the medium/high level of NBTs [11]. This two-level of classification of scale-based NBTs with 4 as the cut-off point is comparable to the single item classification of NBTs, where 4 can also be used to reclassify the three levels of NBTs into two levels: NBTs_Low and NBTs_Medium/High. The purpose of this classification of NBTs is to see if results of discriminant analysis are comparable between the single-item measure and the multi-item subscale. Fifth and finally, single item classification of NBTs were compared with scale-based classification of NBTs using discriminant analysis with the four socio-demographic variables and five attitudinal factors as predictors. A flowchart showing the analysis steps is presented in Figure 2.

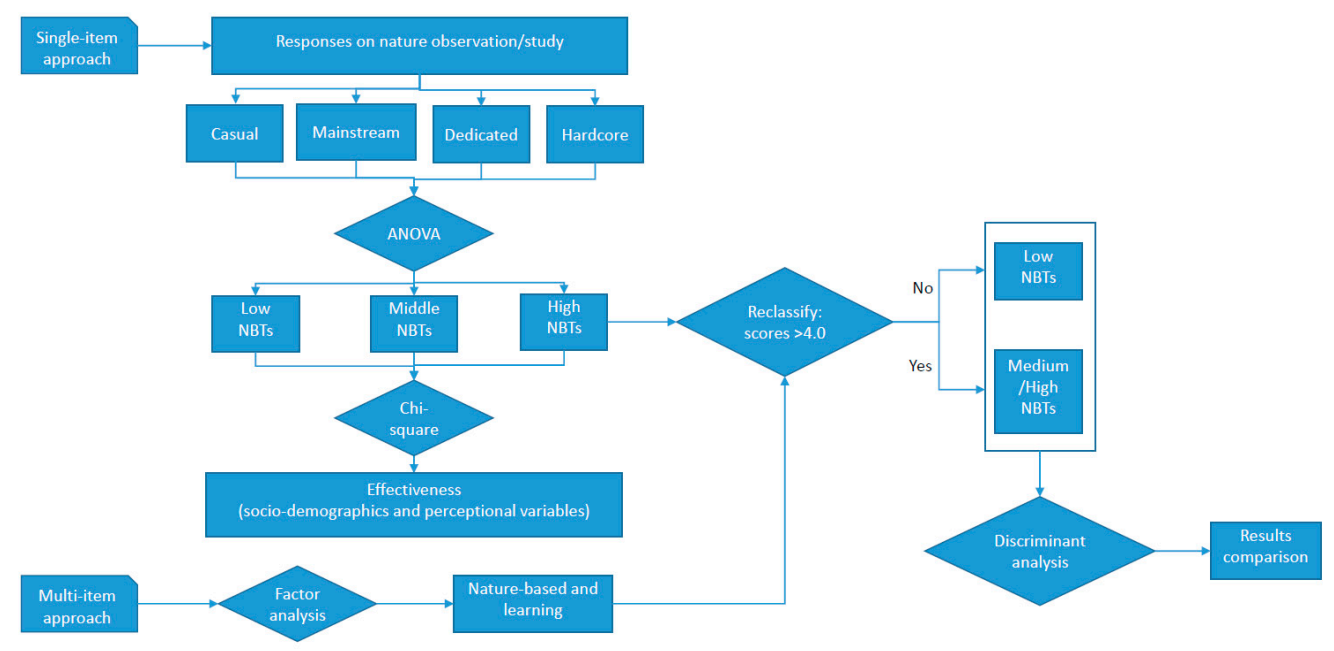

Figure 2. Analysis flowchart. NBTs: nature-based travelers.

\section{Results}

\subsection{Response Rate}

A total of 4994 individuals, who reported to be outside visitors (i.e., non-locals), were surveyed when approached at the 21 locations/events across the county. Of this number, 63 were identified as locals after a further look at their reported zip codes. These 63 locals were then screened out and excluded from further analysis. Thus, the total number of non-local visitors approached was 4931 . Of this number, 2692 visitors were willing to fill out the questionnaire, resulting in a response rate of $54.6 \%$.

\subsection{Socio-Demographic Characteristics}

The survey sample shows that females (56.1\%) outnumbered males (43.9\%). A majority of respondents were $40-54$ years old $(39.7 \%)$, well-educated $(39.3 \%$ and $37.2 \%$ of respondents had at least one college degree and graduate degree, respectively), and affluent ( $45.0 \%$ of respondents had an annual family income of more than $\$ 100,000$ ).

\subsection{Trip Characteristics}

In terms of trip characteristics, most respondents (81.8\%) were repeaters (vs. $18.2 \%$ first timers), and $57.0 \%$ of respondents traveled with kids. Most of the respondents $(88.1 \%)$ provided comments on the survey. Respondents were almost evenly distributed across seasons (27.9\%, 23.3\%, $22.3 \%$, and $26.5 \%$ were surveyed in summer, fall, winter, and spring, respectively). Finally, nearly one-third (29.6\%) of respondents visited one of the two resorts-Adventure Sports Center International (ASCI) and WISP Ski Resort—and $25.1 \%$ of respondents visited state parks in the county. 


\subsection{Factor Analysis}

Table 1 presents results of the factor analysis of the 14 items measuring visitors' perceived importance of attractions. Three factors-“active attractions", "passive attractions", and "cultural attractions" - were derived from these items. They together explain $61.18 \%$ of the total variance. The Cronbach's alpha for each subscale is greater than 0.70 , indicating a good construct reliability.

Table 1. Summary results of factor analysis of perceived importance of attractions.

\begin{tabular}{|c|c|c|c|c|c|}
\hline \multirow{2}{*}{$\begin{array}{l}\text { Factor (Proportion): } \\
\text { Scale Name and Items }\end{array}$} & \multirow{2}{*}{$M$} & \multirow{2}{*}{$S D$} & \multicolumn{3}{|c|}{ Rotated (Varimax) Factors } \\
\hline & & & 1 & 2 & 3 \\
\hline Factor 1: Active attractions & 3.06 & 1.06 & & & \\
\hline Golf courses & 2.49 & 1.40 & 0.721 & -0.011 & 0.192 \\
\hline Ski resorts & 3.49 & 1.51 & 0.743 & 0.165 & 0.005 \\
\hline Artificial whitewater course & 2.83 & 1.38 & 0.757 & 0.211 & 0.134 \\
\hline Water sports & 3.51 & 1.38 & 0.730 & 0.362 & 0.053 \\
\hline Fishing & 3.04 & 1.45 & 0.555 & 0.226 & 0.263 \\
\hline Factor 2: Passive attractions & 3.91 & 0.96 & & & \\
\hline Trails & 3.61 & 1.23 & 0.215 & 0.788 & 0.185 \\
\hline Scenery & 4.23 & 1.00 & 0.145 & 0.841 & 0.142 \\
\hline State parks & 3.97 & 1.15 & 0.167 & 0.844 & 0.205 \\
\hline Fall foliage & 3.79 & 1.25 & 0.133 & 0.653 & 0.351 \\
\hline Factor 3: Cultural attractions & 2.78 & 0.96 & & & \\
\hline Camping & 2.86 & 1.41 & 0.245 & 0.392 & 0.444 \\
\hline Farm tours/corn mazes & 2.15 & 1.12 & 0.203 & 0.115 & 0.793 \\
\hline Historic sites & 2.88 & 1.20 & 0.009 & 0.318 & 0.783 \\
\hline Festival/events & 3.33 & 1.24 & 0.261 & 0.303 & 0.666 \\
\hline Eigenvalues & & & 5.64 & 1.73 & 1.19 \\
\hline$\%$ of variance & & & 40.26 & 12.39 & 8.53 \\
\hline Cumulative \% & & & & 52.65 & 61.18 \\
\hline Standardized Cronbach's $a$ & & & 0.80 & 0.85 & 0.76 \\
\hline
\end{tabular}

Note: Kaiser-Meyer-Olkin (KMO) = 0.90; Bartlett's Test of Sphericity, $p<0.001$. "Real estate tour/search" was excluded because of its cross loadings on both factors.

Two factors- "heritage and local products" and "alcohol and dining out"—were obtained from the 12 items measuring visitors' perceptions of the importance of products (Table 2). These two factors explain $54.43 \%$ of the total variance, with the first factor accounting for a large portion $(42.00 \%)$ with a higher level of reliability $(a=0.88$ ). The $a$ value for the second factor was 0.61 , slightly lower than the cut-off point of 0.70 . This lower $a$ value was still acceptable as discussed above.

Table 2. Summary results of factor analysis of perceived importance of products.

\begin{tabular}{|c|c|c|c|c|}
\hline \multirow{2}{*}{$\begin{array}{l}\text { Factor (Proportion): } \\
\text { Scale Name and Items }\end{array}$} & \multirow{2}{*}{$M$} & \multirow{2}{*}{$S D$} & \multicolumn{2}{|c|}{ Rotated (Varimax) Factors } \\
\hline & & & 1 & 2 \\
\hline Factor 1: Heritage and local products & 1.98 & 0.93 & & \\
\hline Books and music & 2.05 & 1.16 & 0.565 & 0.308 \\
\hline Collectibles/jewelry & 1.67 & 1.00 & 0.768 & 0.048 \\
\hline Art galleries & 1.70 & 1.00 & 0.770 & 0.110 \\
\hline Antiques & 1.94 & 1.15 & 0.800 & 0.050 \\
\hline Souvenirs & 2.04 & 1.12 & 0.505 & 0.297 \\
\hline Locally made products & 2.63 & 1.26 & 0.743 & 0.276 \\
\hline Glassware/pottery & 1.98 & 1.17 & 0.833 & 0.128 \\
\hline Amish products & 2.13 & 1.23 & 0.745 & 0.179 \\
\hline Factor 2: Alcohol and dining out & 2.94 & 1.05 & & \\
\hline Sporting goods & 2.46 & 1.31 & 0.141 & 0.700 \\
\hline Sunday sales of alcohol & 2.60 & 1.63 & -0.017 & 0.735 \\
\hline Dining out & 3.76 & 1.19 & 0.194 & 0.721 \\
\hline Eigenvalues & & & 5.03 & 1.49 \\
\hline$\%$ of variance & & & 42.00 & 12.43 \\
\hline Cumulative \% & & & & 54.43 \\
\hline Standardized Cronbach's $a$ & & & 0.88 & 0.61 \\
\hline
\end{tabular}

Note: $\mathrm{KMO}=0.89$; Bartlett's Test of Sphericity, $p<0.001$. One item on sporting goods was excluded because of its heavy cross loadings on two factors. 
The results of factor analysis for the motivation measure are presented in Table 3. Factor analysis resulted in two factors_-"nature-based and learning" and "relaxation"—which together explain $53.20 \%$ of the total variance. The $a$ value for each factor was 0.81 and 0.70 , respectively, suggesting a good subscale reliability. The subscale "nature-based and learning" was later used as a multi-item approach to classify visitors into two levels of NBTs, as discussed earlier.

Table 3. Summary results of factor analysis of items measuring motivation.

\begin{tabular}{|c|c|c|c|c|}
\hline \multirow{2}{*}{$\begin{array}{l}\text { Factor (Proportion): } \\
\text { Scale Name and Items }\end{array}$} & \multirow{2}{*}{$M$} & \multirow{2}{*}{$S D$} & \multicolumn{2}{|c|}{ Rotated (Varimax) Factors } \\
\hline & & & 1 & 2 \\
\hline Factor 1: Nature-based and learning & 3.54 & 0.07 & & \\
\hline Rural life activities & 3.74 & 1.04 & 0.553 & 0.413 \\
\hline To experience local flavor & 3.68 & 1.04 & 0.658 & 0.287 \\
\hline Four weather activities & 3.32 & 1.15 & 0.668 & 0.099 \\
\hline Opportunities to learn/to be edu-tained & 3.15 & 1.12 & 0.808 & 0.087 \\
\hline Adventure seeking & 3.92 & 1.01 & 0.552 & 0.370 \\
\hline To be entertained/theatre & 3.16 & 1.14 & 0.682 & 0.037 \\
\hline Nature observation & 3.85 & 1.04 & 0.562 & 0.358 \\
\hline Factor 2: Relaxation & 4.27 & 0.74 & & \\
\hline Opportunities for children & 3.88 & 1.11 & 0.168 & 0.737 \\
\hline Have a good time with family & 4.45 & 0.85 & 0.103 & 0.881 \\
\hline Rest/relaxation & 4.46 & 0.84 & 0.188 & 0.683 \\
\hline Eigenvalues & & & 4.03 & 1.29 \\
\hline$\%$ of variance & & & 40.30 & 12.90 \\
\hline Cumulative \% & & & & 53.20 \\
\hline Standardized Cronbach's $a$ & & & 0.81 & 0.70 \\
\hline
\end{tabular}

Note: $\mathrm{KMO}=0.83$; Bartlett's Test of Sphericity, $p<0.001$.

\subsection{ANOVA}

As aforementioned, respondents were first classified into four types-casual, mainstream, dedicated, and hard-core-based on their responses to the question on natural observation/study using the a priori segmentation approach. Table 4 presents results of ANOVA comparisons between these four groups in terms of their perceived importance of attractions.

Table 4. Comparisons of perceived importance of attractions by nature-based tourist types.

\begin{tabular}{|c|c|c|c|c|c|}
\hline Variable & $\begin{array}{c}\text { (I) } \\
\text { Groups }\end{array}$ & $\begin{array}{c}(\mathrm{J}) \\
\text { Groups }\end{array}$ & $\begin{array}{c}\text { Mean Difference } \\
\text { (I-J) }\end{array}$ & Std. Error & Sig. \\
\hline \multirow{6}{*}{$\begin{array}{l}\text { Cultural } \\
\text { attractions }\end{array}$} & \multirow{3}{*}{ Casual } & Mainstream & -0.15 & 0.07 & 0.278 \\
\hline & & Dedicated & -0.43 & 0.07 & $0.000^{* * *}$ \\
\hline & & Hard-core & -0.80 & 0.07 & $0.000^{* * *}$ \\
\hline & \multirow{2}{*}{ Mainstream } & Dedicated & -0.28 & 0.05 & $0.000^{* * *}$ \\
\hline & & Hard-core & -0.65 & 0.05 & $0.000^{* * *}$ \\
\hline & Dedicated & Hard-core & -0.37 & 0.05 & $0.000^{* * *}$ \\
\hline \multirow{6}{*}{$\begin{array}{l}\text { Active } \\
\text { attractions }\end{array}$} & \multirow{3}{*}{ Casual } & Mainstream & -0.04 & 0.08 & 1.000 \\
\hline & & Dedicated & -0.21 & 0.08 & $0.044^{*}$ \\
\hline & & Hard-core & -0.32 & 0.08 & $0.001^{* *}$ \\
\hline & \multirow{2}{*}{ Mainstream } & Dedicated & -0.18 & 0.06 & $0.019^{*}$ \\
\hline & & Hard-core & -0.28 & 0.06 & $0.000^{* * *}$ \\
\hline & Dedicated & Hard-core & -0.10 & 0.06 & 0.366 \\
\hline \multirow{6}{*}{$\begin{array}{l}\text { Passive } \\
\text { attractions }\end{array}$} & \multirow{3}{*}{ Casual } & Mainstream & -0.17 & 0.07 & 0.091 \\
\hline & & Dedicated & -0.58 & 0.07 & $0.000^{* * *}$ \\
\hline & & Hard-core & -1.02 & 0.07 & $0.000^{* * *}$ \\
\hline & \multirow[b]{2}{*}{ Mainstream } & Dedicated & -0.41 & 0.05 & $0.000^{* * *}$ \\
\hline & & Hard-core & -0.84 & 0.05 & $0.000^{* * *}$ \\
\hline & Dedicated & Hard-core & -0.43 & 0.05 & $0.000^{* * *}$ \\
\hline
\end{tabular}

Note: ${ }^{*} p<0.05,{ }^{* *} p<0.01,{ }^{* * *} p \leq 0.001$. 
As shown, the casual and mainstream groups were not significantly different from each other in all the three factors. However, they differed significantly from the dedicated and hard-core groups. Thus, the casual and mainstream groups were lumped together as one group, the low level of NBTs, while the dedicated group and hard-core group were renamed as medium and high levels of NBTs, respectively.

Table 5 presents the results of ANOVA comparisons between the four groups in their perceptions of product attribute importance. Interestingly, no significant difference existed between the casual group and mainstream group in their perception of heritage and local products, while both groups were significantly different from the dedicated and hard-core groups. This same pattern of perceptions endorses the three-level classification of NBTs based on visitors' perceived importance of attractions. That said, the four groups were not significantly different from one another in their perceptions of alcohol and dining out. This should not be surprising, given that alcohol and dining out can be considered to be one type of basic need for human beings, and thus, people's perceptions of this factor are similar, irrespective of their levels of nature affinity.

Table 5. Comparisons of perceptions of products by nature-based tourist type.

\begin{tabular}{|c|c|c|c|c|c|}
\hline Variable & $\begin{array}{l}\text { (I) } \\
\text { Groups }\end{array}$ & $\begin{array}{l}\text { (J) } \\
\text { Groups }\end{array}$ & $\begin{array}{c}\text { Mean Difference } \\
\text { (I-J) }\end{array}$ & Std. Error & Sig. \\
\hline \multirow{6}{*}{$\begin{array}{l}\text { Heritage and } \\
\text { local products }\end{array}$} & \multirow{3}{*}{ Casual } & Mainstream & -0.14 & 0.07 & 0.234 \\
\hline & & Dedicated & -0.27 & 0.06 & $0.000^{* *}$ \\
\hline & & Hard-core & -0.51 & 0.07 & $0.000^{* *}$ \\
\hline & \multirow{2}{*}{ Mainstream } & Dedicated & -0.13 & 0.05 & $0.034^{*}$ \\
\hline & & Hard-core & -0.37 & 0.05 & $0.000^{* *}$ \\
\hline & Dedicated & Hard-core & -0.24 & 0.05 & $0.000^{* *}$ \\
\hline \multirow{6}{*}{$\begin{array}{l}\text { Alcohol and } \\
\text { dining out }\end{array}$} & \multirow{3}{*}{ Casual } & Mainstream & -0.07 & 0.09 & 1.000 \\
\hline & & Dedicated & -0.08 & 0.08 & 0.682 \\
\hline & & Hard-core & -0.13 & 0.08 & 1.000 \\
\hline & \multirow{2}{*}{ Mainstream } & Dedicated & -0.01 & 0.06 & 1.000 \\
\hline & & Hard-core & -0.05 & 0.06 & 1.000 \\
\hline & Dedicated & Hard-core & -0.05 & 0.06 & 1.000 \\
\hline
\end{tabular}

\subsection{Chi-Square Analysis}

Socio-economic characteristics. The chi-square analysis by gender shows that females were more likely to be NBTs at the high level than were males $(p<0.001)$. However, no significant difference existed between them at the low level. The chi-squared results by age, education, and income show that older respondents were more likely to be NBTs at the high level than were younger respondents $(p<0.01)$. This is consistent with the finding that younger people tend to be less interested in nature than older people $(p<0.01)$. In terms of NBTs at the medium level, no significant difference existed among the three age groups. While education had no impact on the high level of NBTs, it had a significant impact on the low and medium levels of NBTs, with well-educated respondents being more likely to be the medium level of NBTs and less likely to be the low level of NBTs than their less-educated counterparts $(p<0.05)$. Finally, in terms of income's impact on NBTs, no significant differences were found for the medium and high levels of NBTs. However, respondents with a low level of income tended to be more likely to be NBTs at the low level than respondents with higher levels of income.

Trip characteristics. Chi-square results by past experience indicate that repeaters were more likely to be hard-core NBTs than were first timers, whereas no significant differences existed between the two groups in the low and medium categories. The results of the chi-square analysis by other trip characteristics, such as traveling with kids or not, traveling season, and survey locations, indicate that those who traveled with kids were more likely to be NBTs at the low level and less likely at the high 
level compared with respondents without kids in the sample. While summer, spring, and fall had no significant impact on the level of the NBTs, winter was the season in which respondents tended to be NBTs at the low level. Finally, resort respondents were significantly more likely to be low-level NBTs and significantly less likely to be high-level NBTs. On the contrary, respondents surveyed at state parks were more likely to be NBTs at the high level and less likely to be NBTs at the low level $(p<0.001)$.

\subsection{Discriminant Analysis}

Single-item classification. Discriminant analysis was conducted to predict the memberships of NBTs based on their socio-demographics and their perceived importance of attractions and products. The results are presented in Table 6. The most predictive variables were passive attractions (e.g., trails, scenery, state parks, and fall foliage), which had the largest unstandardized coefficient 0.931 , followed by cultural attractions $(0.272)$ and heritage and local products $(0.256)$. In contrast, socio-demographic variables had smaller coefficients. All the predictors explained nearly one-third (34.2\%) of the total variance. Overall, $70.2 \%$ of cases were correctly classified, with 47 ungrouped cases.

Table 6. Classification results by socio-demographics and attitudinal variables (single item).

\begin{tabular}{cccc}
\hline \multirow{2}{*}{ Actual Group } & \multicolumn{2}{c}{ Predicated Group Membership } & \multirow{2}{*}{ Total } \\
\cline { 2 - 3 } & NBTs_Low & NBTs_Medium and High & \\
\hline NBTs_Low & $136(27.1 \%)$ & $366(72.9 \%)$ & $502(100.0 \%)$ \\
NBTs_Medium and High & $92(8.9 \%)$ & $941(91.1 \%)$ & $1033(100.0 \%)$ \\
Ungrouped cases & $15(31.9 \%)$ & $32(68.1 \%)$ & $47(100.0 \%)$ \\
\hline
\end{tabular}

Scale-based classification. The same procedures of discriminant analysis were repeated for scale-based classification of NBTs. The results are presented in Table 7. The most predictive variables were heritage and local products (unstandardized coefficient $=0.523$ ), followed by passive attractions (0.292), and cultural attractions (0.263). As with the single-item classification, the coefficients for socio-demographic variables were also small. Similar to the single-item classification, nearly one-third $(31.3 \%)$ of the total variance was explained by the independent variables. Overall, $79.6 \%$ of cases were correctly classified, with 121 ungrouped cases.

Table 7. Classification results by socio-demographics and attitudinal variables (scale-based).

\begin{tabular}{cccc}
\hline \multirow{2}{*}{ Actual Group } & \multicolumn{2}{c}{ Predicated Group Membership } & \multirow{2}{*}{ Total } \\
\cline { 2 - 3 } & NBTs_Low & NBTs_Medium and High & \\
\hline NBTs_Low & $1127(97.7 \%)$ & $26(2.3 \%)$ & $1153(100.0 \%)$ \\
NBTs_Medium and High & $272(88.3 \%)$ & $36(11.7 \%)$ & $308(100.0 \%)$ \\
Ungrouped cases & $117(96.7 \%)$ & $4(3.3 \%)$ & $121(100.0 \%)$ \\
\hline
\end{tabular}

\section{Discussion and Conclusions}

The main purpose of this study was to identify NBTs in a rural area using a single-item approach. The results demonstrate that NBTs can be segmented into three levels: low, medium, and high, based on their responses to a single item measuring their motivation to observe/study nature. Significant differences existed between the three groups of NBTs in socio-demographic variables and trip characteristics. These findings are generally consistent with those in the literature on NBTs' or ecotourists' characteristics, suggesting the appropriateness of the use of the single-item approach for market segmentation of NBTs. For example, it has been found that high-level NBTs are mostly females, older, well-educated, and affluent, confirming some of the previous studies $[27,30]$.

In terms of trip characteristics, repeaters were found to be more dedicated to nature than first timers. This could be explained by two reasons. First, repeaters may have developed a higher level of 
place attachment than first timers. Consequently, they may have been more emotionally bonded to the destination and its nature-based areas. Second, repeaters may have been more specialized and knowledgeable about the natural areas at the destination and more dedicated to nature than first timers. It has been argued that "specialization is a process that occurs over time" [45], and past experience and place attachment are conceptually linked to recreation specialization. A specialist nature tourist is defined as someone whose main reason to visit a destination is for nature observation/study, while nature is only one of the reasons for a generalist nature tourist [46]. Thus, repeaters who are more dedicated to nature could also be classified as specialist nature tourists.

It is worth noting that people's responses to the question on natural observation/study varied by season, with winter receiving the lowest scores on the single-item measure of natural observation/study, whereas no significant differences existed between summer, spring, and fall. While a four-season comparison study on ecotourism/NBT is rare, one study [30] did compare tourists' responses to questions on ecotourism/NBT between two seasons, summer and spring, finding that respondents were more likely to identify themselves as ecotourists in spring than in summer. Priskin argues [31], "nature-based tourists in the spring seem to fit between the mainstream and the dedicated nature tourists according to Lindberg's classification" [19].

Another interesting finding was that the people's responses to questions on their interests in nature also varied with location, with respondents surveyed at state parks being more likely to be high-level NBTs, whereas respondents at the two resorts were more likely to be low-level NBTs. This finding indicates that different perceptions of nature affinity may arise from the differences between locations with different levels of natural elements. Similar findings have also been reported in other studies. For example, one study [47] found that visitors tend to be more positive in their perceptions of urban forests when surveyed in a location with diverse and dense urban forests. Another study [7] also reported that tourists assess natural areas and their gateway cities differently with the former being more likely to create a positive image than the latter. Locations with different types of on-site factors (i.e., presentation platform and support services) have also been found to influence visitors' perceptions and satisfaction [48].

It should be noted that older respondents were more dedicated to nature than the younger respondents, and people traveling with kids tended to be NBTs at the low level. This finding echoes some researchers' [49] concerns that love of nature in the United States is being replaced with love of electronic media. We also relate this finding to the two concepts of "nature deficit disorder" and "biophilia." While we as humans have an instinctive affinity with nature [50], our behaviors tend to contradict this theory, with kids spending too much time indoors, playing video games or watching $\mathrm{TV}$, and parents fearing dangers and diseases in natural areas [51].

\subsection{Research Implications}

This study has important theoretical, methodological, and managerial implications. Theoretically, previous studies have used environmental attitudes to identify ecotourists either at natural areas [30] or non-natural areas [16]. Although people's attitudes may not easily change across locations, it is very likely that locations with distinct compositions of resources will influence the way in which people respond. Thus, an international comparison of NBTs or ecotourists can only be made meaningful under similar, if not exactly the same, circumstances [16].

Methodologically, the use of the single-item approach is appropriate for the market segmentation of NBTs in the rural area. First, discriminant analysis shows that the single-item approach was as effective as the multi-item approach to classify cases into the correct membership groups. Several studies (albeit not in the recreation/tourism field) have evidenced that a single-item scale is acceptable. For instance, a study on adult patients with cystic fibrosis [52] found that a single-item quality of life scale had good reliability and validity compared with the multi-item Cystic Fibrosis Quality of Life Questionnaire. Another study [53] also reported that a single-item measure was comparable to a multi-item measure of self-efficacy. These findings go against the maxim in psychometrics that "the 
more items in self-report measures of psychological constructs, the better" (pp. 898) [54]. Moreover, the use of a single-item measure can reduce the survey fatigue that may be caused by a lengthy questionnaire and thus may increase the response rate and improve the quality of data collection.

Managerially, natural beauty can be a double-edged sword for an area. Beautiful scenery is the magnet that attracts not only visitors, but also second home owners. The survey shows that $24.4 \%$ of respondents were either extremely $(6.1 \%)$, very $(6.6 \%)$, or moderately $(11.7 \%)$ interested in relocating to the survey area, with the top reason being environmental amenities, accounting for $30.5 \%$ of all expressed reasons. While second home owners can make a significant contribution to the local economy, the high demand of relocation may increase prices of local products and real estate, which, in turn, may affect the quality of life of local residents. On the other hand, the development of real estate may pose a threat to the integrity of the natural resources in the area. Thus, a balanced approach that prevents over-tourism needs to be adopted in the area-a concern expressed by some visitors. For instance, one visitor commented, "Natural beauty is the reason we come. The build-up of houses etc. at Deep Creek is enough to make us rethink coming here at all if it gets much worse. Seriously, we come for quiet and a closer experience with nature. We [do not] need more Subways and Dollar stores - we can get those [to] home. Capitalize on untouched woods [and] forests, deer streams, clean air, quiet. You'll do really well, with focus on adventurous interaction with nature." A similar comment was made by another visitor, who wrote, "I feel that, to this point, Garrett County has achieved a reasonable balance between developing a residential, seasonal residential, commercial recreational complex (Deep Creek) and conserving its natural resource of forested mountains, flowing streams and open space. However, it is my impression that the county is nearing a tipping point, or threshold, beyond which the county will begin to lose attractiveness to those attracted by natural landscape and the authentic experience they offer".

Because the primary objective of NBT is to promote understanding and appreciation of nature through direct interactions with the natural environment [38], the county needs to place a higher priority on the protection of natural resources and scenic beauty, on the one hand, and to provide opportunities for natural observation and study on the other. For the latter, the area may need to have a multi-function nature education center that presents exhibits on animals/plants and biodiversity/ecosystem, offers activities for groups with family and kids, and provides educational programs for students' field trips. In addition, nature-oriented videos can also be played at non-natural places, such as hotels and restaurants. These measures may reinforce/enhance people's love for nature and promote/facilitate positive behavioral transformations not only on-site as visitors, but, more importantly and meaningfully, at home as citizens.

\subsection{Research Limitations and Future Research Needs}

This study is not without limitations. First, although it is a four-season survey conducted at a variety of locations that are representative of the county's attractions and tourism resources, most surveys were conducted on the weekends. Weekday visitors may be different from weekend visitors in terms of their socio-demographics and psychographic characteristics. Thus, the market segmentation may not be representative of the whole market for the area. Surveys with a balance of weekdays and weekends need to be considered in the future. Second, visitors were surveyed in such a way that whoever was willing to complete the questionnaire was asked to do so. This may have created a selection bias. To avoid this bias, future studies need to adopt the respondent-selection method used by the United States Department of Agriculture (USDA) Forest Service's National Visitor Use Monitoring (NVUM) program, wherein the person in the group who had the most recent birthday and is at least 16 years of age is the person selected to complete the survey [55]. Finally, the appropriateness of the use of the single-item measure for NBT market segmentation was determined by the measure's effectiveness to differentiate socio-demographic variables and trip characteristics and also by its comparable results with multi-item scale measures. While this type of comparison may serve, to some degree, as an indication of the validity of the single-item measure, its reliability was not tested. 
The repeatability of the single-item measure needs to be assessed in the next round of market surveys for the same area.

Author Contributions: J.D. contributed to the conception and design, data collection, data analysis, and manuscript preparation. J.L. participated in data collection and contributed to result interpretation.

Acknowledgments: This study was jointly funded by the Garrett County Chamber of Commerce, Maryland, USA, through a grant from the Appalachian Regional Commission and the USDA National Institute of Food and Agriculture McIntire Stennis project [WVA00803] (for J.D.), and by the Zhejiang Soft Science Research Program [2019C35085] (for J.L., who stayed at West Virginia University as a Visiting Scholar from September 2008 to January 2009). Thanks also go to the five anonymous reviewers for their insightful comments on how this paper should be improved.

Conflicts of Interest: The authors declare no conflicts of interest.

\section{References}

1. Goodwin, H. In pursuit of ecotourism. Biodivers. Conserv. 1996, 5, 277-291. [CrossRef]

2. Buckley, R. Ecotourism: Principles and Practices; CABI: Oxfordshire, UK, 2009; ISBN 978-1-84593-457-6.

3. Christ, C.; Hillel, O.; Matus, S.; Sweeting, J. Tourism and Biodiversity: Mapping Tourism's Global Footprint. Available online: http://www.elkhornsloughctp.org/uploads/files/1479937017-Tourism\% 20and\%20Biodiversity\%20Mapping\%20Tourism\%27s\%20Global\%20Footprint-2003649\%20\%281\%29.pdf (accessed on 14 October 2018).

4. Lee, T.H. A structural model to examine how destination image, attitude, and motivation affect the future behavior of tourists. Leis. Sci. 2009, 31, 215-236. [CrossRef]

5. Wu, Y.; Wang, H.; Ho, Y. Urban ecotourism: Defining and assessing dimensions using fuzzy number construction. Tour. Manag. 2010, 31, 739-743. [CrossRef]

6. Fredman, P.; Wall-Reinius, S.; Grunden, A. The nature of nature in nature-based tourism. Scand. J. Hosp. Tour. 2012, 12, 289-309. [CrossRef]

7. Line, N.D.; Costen, W. Nature-based tourism destinations: A dyadic approach. J. Hosp. Tour. Res. 2017, 41, 278-300. [CrossRef]

8. Priskin, J. Assessment of natural resources for nature-based tourism: The case of the Central Coast Region of Western Australia. Tour. Manag. 2001, 22, 637-648. [CrossRef]

9. Hall, C.M. Biosecurity and ecotourism. In Critical Issues in Ecotourism: Understanding a Complex Tourism Phenomenon, 1st ed.; Higham, J., Ed.; Routledge: London, UK, 2007; ISBN 100750668784.

10. Dolnicar, S. Beyond commonsense segmentation: A systematics of segmentation approaches in tourism. J. Travel Res. 2004, 42, 244-250. [CrossRef]

11. Boley, B.B.; Nickerson, N.P. Profiling geotravelers: An a priori segmentation identifying and defining sustainable travelers using the Geotraveler Tendency Scale (GTS). J. Sustain. Tour. 2013, 21, 314-330. [CrossRef]

12. Hanlan, J.; Fuller, D.; Wilde, S.J. Segmenting Tourism Markets: A Critical Review. Available online: http: / / citeseerx.ist.psu.edu/viewdoc/download?doi=10.1.1.1033.4640\&rep=rep1\&type=pdf (accessed on 24 March 2018).

13. Kashyap, R.; Bojanic, D.C. A structural analysis of value, quality, and price perceptions of business and leisure travelers. J. Travel Res. 2000, 39, 45-51. [CrossRef]

14. Klemm, M.S. Tourism and ethnic minorities in Bradford: The invisible segment. J. Travel Res. 2002, 41, 85-91. [CrossRef]

15. Biljana, J.; Cornwell, T.; Mather, D. Exploring the usefulness of an ecotourism interest scale. J. Travel Res. 2002, 40, 259-269.

16. Deng, J.; Li, J. Self-identification of ecotourists. J. Sustain. Tour. 2015, 23, 255-279. [CrossRef]

17. Formica, S.; Uysal, M. Segmentation of Travelers Based on Environmental Attitudes. J. Hosp. Leis. Mark. 2002, 9, 35-49. [CrossRef]

18. Zografos, C.; Allcroff, D. The environmental values of potential ecotoursts: A segmentation study. J. Sustain. Tour. 2007, 15, 44-66. [CrossRef] 
19. Lindberg, K. Policies for Maximizing Nature Tourism's Ecological and Economic Benefits. Available online: http:/ / citeseerx.ist.psu.edu/viewdoc/download?doi=0.1.1.536.5828\&rep=rep1\&type=pdf (accessed on 1 February 2019).

20. Ballantine, J.L.; Eagles, P.F. Defining Canadian ecotourists. J. Sustain. Tour. 1994, 2, 210-214. [CrossRef]

21. Dunlap, R.E.; Van Liere, K.D.; Mertig, A.G.; Jones, R.E. Measuring endorsement of the New Ecological Paradigm: A revised NEP scale. J. Soc. Issues 2000, 56, 425-442. [CrossRef]

22. Gutman, J. A means-end chain model based on consumer categorization process. J. Mark. 1982, 46, 60-72. [CrossRef]

23. López-Mosquera, N.; Sánchez, M. The influence of personal values in the economic-use valuation of peri-urban green spaces: An application of the means-end chain theory. Tour. Manag. 2011, 32, 875-889. [CrossRef]

24. Jiang, S.; Scott, N.; Ding, P. Using means-end chain theory to explore travel motivation: An examination of Chinese outbound tourists. J. Vacat. Mark. 2015, 21, 87-100. [CrossRef]

25. Kim, B.; Kim, S.S.; King, B. The sacred and the profane: Identifying pilgrim traveler value orientations using means-end theory. Tour. Manag. 2016, 56, 142-155. [CrossRef]

26. Mowforth, M. Ecotourism: Terminology and Definitions; Research Report Series, No. 1; Department of Geographical Sciences, University of Plymouth: Plymouth, UK, 1993.

27. Weaver, D.B.; Lawton, L. Overnight ecotourist market segmentation in the Gold Coast Hinterland of Australia. J. Travel Res. 2002, 40, 270-280. [CrossRef]

28. Dolnicar, S. Insights into sustainable tourists in Austria: A data-based a priori segmentation approach. J. Sustain. Tour. 2004, 12, 209-218. [CrossRef]

29. Hvenegaard, G.T. Using tourist typologies for ecotourism research. J. Ecotour. 2002, 1, 7-18. [CrossRef]

30. Priskin, J. Characteristics and perceptions of coastal and wildflower nature-based tourists in the Central Coast Region of Western Australia. J. Sustain. Tour. 2003, 11, 499-528. [CrossRef]

31. Tao, C.; Eagles, P.F.J.; Smith, S.L.J. Profiling Taiwanese ecotourists using a self-definition approach. J. Sustain. Tour. 2004, 12, 149-168. [CrossRef]

32. Dolnicar, S.; Long, P. Beyond ecotourism: The environmentally responsible tourist in the general travel experience. Tour. Anal. 2009, 14, 503-513. [CrossRef]

33. U.S. Census Bureau. American Fact Finder: Community Facts. Available online: https://factfinder.census. gov/faces/nav/jsf/pages/community_facts.xhtml\# (accessed on 25 January 2018).

34. Naoi, T.; Airey, D.; Iijima, S.; Niininen, O. Visitors' evaluation of an historical district: Repertory Grid Analysis and Laddering Analysis with photographs. Tour. Manag. 2006, 27, 420-436. [CrossRef]

35. Fairhurst, A.; Costello, C.; Holmes, A.F. An examination of shopping behavior of visitors to Tennessee according to tourist typologies. J. Vacat. Mark. 2007, 13, 311-319. [CrossRef]

36. Meng, F.; Tepanon, Y.; Uysal, M. Measuring tourist satisfaction by attribute and motivation: The case of a nature-base resort. J. Vacat. Mark. 2008, 14, 41-56. [CrossRef]

37. Parsons, E.C.M.; Warburton, C.A.; Woods-Ballard, A.; Hughes, A.; Johnston, P.; Bates, H.; Luck, M. Whale-watching tourists in west Scotland. J. Ecotour. 2003, 2, 93-113. [CrossRef]

38. Newsome, D.; Moore, S.A.; Dowling, R.K. Natural Area Tourism: Ecology, Impacts and Management; Channel View: Clevedon, UK, 2002; ISBN 1873150245.

39. Comrey, A.; Lee, H. A First Course in Factor Analysis, 2nd ed.; Lawrence Erlbaum Associates: Hillsdale, NJ, USA, 1992; ISBN 0805810625.

40. Nunnally, J.C. Psychometric Theory, 3rd ed.; McGraw-Hill: New York, NY, USA, 1994; ISBN 007047849X.

41. Aron, A.; Aron, E.N. Statistics for Psychology, 5th ed.; Prentice-Hall: Englewood Cliffs, NJ, USA, 2008; ISBN 0136010571.

42. Hair, J.F.; Black, W.C.; Babin, B.J.; Anderson, R.E. Multivariate Data Analysis, 7th ed.; Prentice Hall: Upper Saddle River, NJ, USA, 2010; ISBN 0138132631.

43. Boley, B.B.; Nickerson, N.P.; Bosak, K. Measuring geotourism: Developing and testing the geotraveler tendency scale. J. Travel Res. 2011, 50, 567-578. [CrossRef]

44. Agresti, A. Categorical Data Analysis, 2nd ed.; Wiley: New York, NY, USA, 2002; ISBN 9780470463635.

45. Bricker, K.S.; Kerstetter, D.L. Level of specialization and place attachment: An exploratory study of whitewater recreationists. Leis. Sci. 2000, 22, 233-257. 
46. Mehmetoglu, M. A case study of nature-based tourists: Specialists versus generalists. J. Vacat. Mark. 2005, 11, 357-369. [CrossRef]

47. Deng, J.; Andrada, R.; Pierskalla, C. Visitors' and residents' perceptions of urban forests for leisure in Washington D.C. Urban For. Urban Green. 2018, 28, 1-11. [CrossRef]

48. Jensen, Ø.; Li, Y.; Uysal, M. Visitors' satisfaction at managed tourist attractions in Northern Norway: Do on-site factors matter? Tour. Manag. 2017, 63, 277-286. [CrossRef]

49. Pergams, O.R.W.; Zaradic, P.A. Is love of nature in the US becoming love of electronic media? 16-year downtrend in national park visits explained by watching movies, playing video games, internet use, and oil prices. J. Environ. Manag. 2006, 80, 387-393. [CrossRef] [PubMed]

50. Wilson, E.O. Biophilia and the conservation ethic. In The Biophilia Hypothesis, 1st ed.; Kellert, S.R., Wilson, E.O., Eds.; Island Press: Washington, DC, USA, 1993; ISBN 1559631473.

51. Cohen, D. Why Kids Need to Spend Time in Nature. Available online: https://childmind.org/article/whykids-need-to-spend-time-in-nature/ (accessed on 17 September 2018).

52. Yohannes, A.M.; Dodd, M.; Morris, J.; Webb, K. Reliability and Validity of a Single Item Measure of Quality of Life Scale for Adult Patients with Cystic Fibrosis. Available online: http://www.hqlo.com/content/9/1/105 (accessed on 1 February 2019).

53. Hoeppner, B.B.; Kelly, J.F.; Urbanoski, K.A.; Slaymaker, V. Comparative utility of a single-item vs. multiple-item measure of self-efficacy in predicting relapse among young adults. J. Subst. Abus. Treat. 2011, 41, 305-312. [CrossRef]

54. Gardner, D.G.; Cummings, L.L.; Dunham, R.B.; Pierce, J.L. Single-item versus multiple-item measurement scales: An empirical comparison. Educ. Psychol. Meas. 1998, 58, 898-915. [CrossRef]

55. USDA Forest Service. NVUM Interviewer Handbook. Available online: https://www.fs.fed.us/recreation/ programs/nvum/reference/index.shtml (accessed on 22 September 2018).

(C) 2019 by the authors. Licensee MDPI, Basel, Switzerland. This article is an open access article distributed under the terms and conditions of the Creative Commons Attribution (CC BY) license (http:/ / creativecommons.org/licenses/by/4.0/). 